\title{
Within-session variability as quality control for oscillometry in health and disease
}

\author{
Louise M. Harkness ${ }^{1,2,3}$, Kieran Patel ${ }^{1}$, Farid Sanai ${ }^{1,2,3}$, Sandra Rutting $\mathbb{B}^{1,3}$, Alice M. Cottee $\mathbb{B}^{1,4}$,

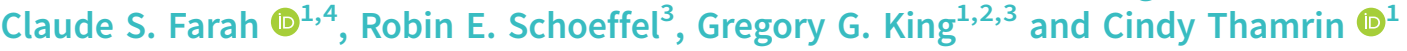

${ }^{1}$ Airway Physiology and Imaging Group, Woolcock Institute of Medical Research, University of Sydney, Glebe, NSW, Australia. ${ }^{2}$ NHMRC Centre of Excellence in Severe Asthma, New Lambton Heights, NSW, Australia. ${ }^{3}$ Dept of Respiratory Medicine, Royal North Shore Hospital, St Leonards, NSW, Australia. ${ }^{4}$ Dept of Thoracic Medicine, Concord Repatriation General Hospital, Concord, NSW, Australia.

Corresponding author: Cindy Thamrin (cindy.thamrin@woolcock.org.au)

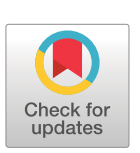

Copyright @The authors 2021

This version is distributed under the terms of the Creative Commons Attribution NonCommercial Licence 4.0. For commercial reproduction rights and permissions contact permissions@ersnet.org

This article has supplementary material available from openres.ersjournals.com

Received: 29 Jan 2021

Accepted: 29 May 2021

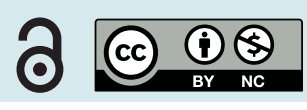

Shareable abstract (@ERSpublications)

Within-session variability of oscillometry indices is intrinsically higher in disease. Quality control should first focus on technical acceptability of measurements, i.e. by removing artefacts and outliers over reducing variability, and CoVs up to $15-20 \%$ should still be reportable. https://bit.ly/3w7qbIR

Cite this article as: Harkness LM, Patel K, Sanai F, et al. Within-session variability as quality control for oscillometry in health and disease. ERJ Open Res 2021; 7: 00074-2021 [DOI: 10.1183/23120541.000742021].

\section{Abstract}

Oscillometry is increasingly adopted in respiratory clinics, but many recommendations regarding measurement settings and quality control remain subjective. The aim of this study was to investigate the optimal number of measurements and acceptable within-session coefficient of variation $(\mathrm{CoV})$ in health, asthma and COPD.

15 healthy, 15 asthma and 15 COPD adult participants were recruited. Eight consecutive 30-s measurements were made using an oscillometry device, from which resistance at $5 \mathrm{~Hz}\left(R_{\mathrm{rs}_{5}}\right)$ was examined. The effect of progressively including a greater number of measurements on $R_{\mathrm{rs}_{5}}$ and its within-session CoV was investigated. Data were analysed using one-way repeated-measures ANOVA with Bonferroni post hoc test.

The $\operatorname{CoV}\left(R_{\mathrm{rs}_{5}}\right)$ of the first three measurements was $6.7 \pm 4.7 \%, 9.7 \pm 5.7 \%$ and $12.6 \pm 11.2 \%$ in healthy, asthma and COPD participants, respectively. Both mean $R_{\mathrm{rs}_{5}}$ and $\operatorname{CoV}\left(R_{\mathrm{rs}_{5}}\right)$ were not statistically different when progressively including four to eight measurements. Selecting the three closest $R_{\mathrm{rs}_{5}}$ values over an increasing number of measurements progressively decreased the $\operatorname{CoV}\left(R_{\mathrm{rs}_{5}}\right)$. In order for $\geqslant 95 \%$ of participants to fall within a target $\operatorname{CoV}\left(R_{\mathrm{rs}_{5}}\right)$ of $10 \%$, four or more, five and six measurements were needed in health, asthma and COPD, respectively.

Within-session variability of oscillometry is increased in disease. Furthermore, the higher number of measurements required to achieve a set target for asthma and COPD patients may not be practical in a clinical setting. Provided technical acceptability of measurements is established, i.e. by removing artefacts and outliers, then a $\mathrm{CoV}$ of $10 \%$ is a marker of quality in most patients, but we suggest higher CoVs up to 15-20\% should still be reportable.

\section{Introduction}

The forced oscillation technique, also known as oscillometry, is a method of measuring respiratory system impedance that is noninvasive, noneffort dependent, simple to administer and reproducible. Oscillometry provides detailed respiratory mechanics and sensitivity measures, especially of the small airways. Its utility in a research setting is well established [1, 2], and its clinical use is increasingly recognised [3, 4]. The technique involves superimposing pressure oscillations at the mouth onto resting tidal breathing. Respiratory impedance is then calculated as the ratio between pressure and flow, and can be broken down to resistance $\left(R_{\mathrm{rs}}\right)$, which is a measure of airway calibre, and reactance $\left(X_{\mathrm{rs}}\right)$, which is a measure of the elastic properties of the respiratory system. Both measurements are sensitive to heterogeneous airway narrowing and closure, which typically occurs in airway diseases. 
As oscillometry matures as an emerging clinical test, there is a greater need to standardise testing protocols. Expert recommendations on the nature of the testing sessions have been made [1, 5, 6]; current standards [4] recommend acquiring at least three replicates within a single testing session that are deemed acceptable quality control criteria (visual inspection, within-session coefficient of variation (CoV) and automated signal processing). Minimising the within-session $\mathrm{CoV}$ is desirable, because this will improve the between-session reproducibility of the test.

A target cut-off $\mathrm{CoV}$ of $\leqslant 10 \%$ is recommended for adults and $15 \%$ for children [4], but there is limited empirical evidence supporting these cut-offs. WATTs et al. [7] and RoBinson et al. [8] both found that increasing measurement duration improved $\mathrm{CoV}$ for a fixed number of three measurements, probably due to increased chances of obtaining artefact-free recordings. However, the impact of number of measurements on the ability to achieve a specific target CoV cut-off is unknown. There is a practical constraint on how many repeated measurements can be obtained within a single session within a clinical setting because of potential time constraints and subject fatigue, which may ultimately affect the measurements themselves. Furthermore, these factors may also depend on disease state; TIMmins et al. [9] had previously shown that within-session variability is typically higher in asthma and COPD compared to health.

Therefore, the aim of this study was to investigate the optimal number of measurements and acceptable within-session $\mathrm{CoV}$ in health, asthma and COPD, within a single testing session. In addition, we analysed the number of measurements required to achieve a set target for within-session CoV.

\section{Methods}

\section{Study design}

Three groups of participants were recruited for this study (15 healthy controls, 15 with asthma and 15 with COPD), from the Woolcock Institute of Medical Research and the Royal North Shore Hospital (Sydney, Australia). Subjects attended a single laboratory session during which their demographic data were collected and they undertook standard spirometry, as well as eight consecutive oscillometry measurements. This study was approved by the Human Ethics Review Committee of the Northern Sydney Local Health District (ethics no. LNR/16/HAWKE/11).

\section{Study subjects}

All healthy controls were either nonsmokers or had a smoking history of $\leqslant 10$ pack-years, no reported history of cardiac or pulmonary disease and no history of regular respiratory or cardiac medication use. Participants with asthma had a respiratory physician diagnosis of asthma, were either nonsmokers or had a smoking history of $\leqslant 10$ pack-years, as well as an absence of any respiratory disease other than asthma. COPD was defined as a respiratory physician diagnosis of COPD and the absence of any respiratory disease other than COPD, a smoking history of $\geqslant 10$ pack-years and no exacerbations within the previous 6 weeks; obstruction was confirmed by an $\mathrm{FEV}_{1} / \mathrm{FVC}$ (forced expiratory volume in $1 \mathrm{~s} /$ forced vital capacity) ratio less than the lower limit of normal [10].

\section{Oscillometry}

Participants were instructed to breathe in a relaxed manner on a tremoFlo C-100 oscillometry device (THORASYS Thoracic Medical Systems, Montreal, QC, Canada). Patients sat upright, wearing a nose clip, with their hands firmly pressed against and supporting their cheeks, and thumbs positioned below the chin. After establishing a stable tidal breathing pattern, eight consecutive 30-s measurements were collected. The airwave oscillometry (AOS) perturbation signal was used, which is a pseudorandom noise waveform spanning 5-37 Hz. For this study, we report the resistance $\left(R_{\mathrm{rs}}\right)$ measured at $5 \mathrm{~Hz}\left(R_{\mathrm{rs}_{5}}\right)$ and reactance $\left(X_{\mathrm{rs}}\right)$ measured at $5 \mathrm{~Hz}\left(X_{\mathrm{rs}_{5}}\right)$.

\section{Data analysis}

We investigated the effect of number of measurements on oscillometry parameters and within-session CoV. This was carried out by calculating mean and CoV in three ways: 1) from all measurements; 2) from only the first three measurements; and 3) from only the closest three measurements available. From this, the mean and $\mathrm{CoV}$ of $R_{\mathrm{rs}_{5}}$ was assessed progressively by increasing the number of measurements available for evaluation from four to eight measurements, and comparing against the average of the first three measurements.

We also investigated what constitutes an acceptable within-session CoV. Using target cut-offs for CoV of $5 \%, 10 \%, 15 \%$ and $20 \%$, we successively determined the number of measurements required for at least 
95\% of the population to fall within these cut-offs when the closest three measurements were selected. This was evaluated for the health and disease groups.

\section{Effect of quality control settings}

Given that there remains no general consensus for the appropriate protocol for quality control and cleaning of oscillometry data, we also examined the sensitivity of our results to the effect of different quality control schemes. Four different quality control methods were used. 1) The "sD-based" method: this method excluded any $R_{\mathrm{rs}}$ values that fell beyond a $\pm 5 \mathrm{SD}$ range of the mean. This is the default method in the tremoFlo software (version 1.0.36; THORASYS Thoracic Medical Systems), and is the method used in the main findings presented. 2) The "manual" method: following data collection, whole breaths that contained data artefacts (cough, swallow, vocalisation or breath hold), as apparent on the volume-time trace, were manually excluded from the analysis using the tremoFlo software. 3) The "combined" method: outlier $R_{\mathrm{rs}}$ values $( \pm 5 \mathrm{SD}$ ) were automatically excluded by the tremoFlo software and whole breaths containing data artefacts were additionally and manually removed. 4) The "none" method: no automatic or manual exclusions were applied to the data. In all schemes, negative $R_{\mathrm{rs}}$ values were automatically excluded and within-breath analysis was performed to obtain total, inspiratory and expiratory $R_{\mathrm{rs}}$ and $X_{\mathrm{rs}}$ at $5 \mathrm{~Hz}$ and $19 \mathrm{~Hz}$. Only whole breaths were included for the calculation of inspiratory and expiratory oscillometry parameters.

\section{Statistical analyses}

For all comparisons, repeated-measures one-way ANOVA with post hoc Bonferroni test was used for normally distributed data and Friedman test with Dunn's post hoc test where data were not normally distributed. Post-bronchodilator spirometry of asthma and COPD patients were compared using unpaired t-test. Data are presented as mean \pm sD. Within-session repeatability was assessed using intra-class correlation coefficient (ICC; SPSS version 26, IBM SPSS Inc., Armonk, NY, USA, mixed-effects model, absolute agreement, mean of three raters).

\section{Results}

\section{Participant characteristics}

Participant demographics and lung function are shown in tables 1 and 2. Participants with asthma or COPD were older and had a reduced $\mathrm{FEV}_{1}$ and $\mathrm{FEV}_{1} / \mathrm{FVC}$ ratio compared to healthy controls, with COPD subjects having the lowest $\mathrm{FEV}_{1} / \mathrm{FVC}$ ratio.

Table 2 also shows oscillometry parameters for the healthy, asthma and COPD groups when considering only the first three consecutive 30-s measurements, using the sD-based quality control method (see supplementary material). Participants with asthma or COPD had a higher $R_{\mathrm{rs}_{5}}$ than healthy controls and COPD patients had a more negative reactance than in healthy controls with increased expiratory flow limitation $\left(X_{\mathrm{rS}_{5}}\right.$.in- $X_{\mathrm{rS}_{5}}$.ex). There were no significant differences in $R_{\mathrm{rs}_{5}}$ or $X_{\mathrm{rS}_{5}}$ between asthma and COPD. In both asthma and COPD there was an increased $R_{\mathrm{rs}_{5}}-R_{\mathrm{rs}_{19}}$ and area under the reactance curve $\left(A_{X \mathrm{rs}}\right)$ compared with healthy controls, although no difference between disease groups.

\begin{tabular}{|c|c|c|c|}
\hline & Healthy & Asthma & COPD \\
\hline $\mathrm{N}$ & 15 (4 male) & 15 (6 male) & 15 (10 male) \\
\hline Age (years) & $30.3 \pm 8.5$ & $57.2 \pm 21.2^{\star \star}$ & $71.4 \pm 9.2^{\star \star \star \star}$ \\
\hline BMI $\left(\mathrm{kg} \cdot \mathrm{m}^{-2}\right)$ & $23.1 \pm 2.5$ & $27.1 \pm 4.7^{\star}$ & $26.2 \pm 6.3$ \\
\hline Smoking history (never/current/ex) & $13 / 1 / 1$ & $12 / 1 / 2$ & $0 / 3 / 12$ \\
\hline Smoking history (pack-years) & $0(0,0)$ & $0(0,0.25)$ & 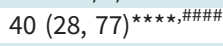 \\
\hline GOLD stages (I/II/III/IV) & - & - & $6 / 5 / 4 / 0$ \\
\hline Pre-BD FEV ${ }_{1}(\%)$ & $96.6 \pm 12.1$ & $90.2 \pm 20.0$ & $59.5 \pm 21.1^{\star \star \star \star, \# \# \# ~}$ \\
\hline Pre-BD FVC (\%) & $99.3 \pm 9.9$ & $110.9 \pm 21.3$ & $90.5 \pm 17.8^{\# \#}$ \\
\hline Pre-BD $\mathrm{FEV}_{1} / \mathrm{FVC}$ & $82.3 \pm 7.2$ & $65.4 \pm 8.1^{\star \star \star}$ & $49.6 \pm 13.8^{\star \star \star \star \star \# \# \# ~}$ \\
\hline Post-BD FEV ${ }_{1}(\%)$ & - & $88.7 \pm 20.0$ & $67.0 \pm 24.1^{\#}$ \\
\hline Post-BD FVC (\%) & - & $105.0 \pm 18.0$ & $94.0 \pm 18.5$ \\
\hline Post-BD FEV $1 /$ FVC & - & $66.3 \pm 8.6$ & $52.1 \pm 15.1^{\# \#}$ \\
\hline
\end{tabular}

Data are presented as mean $\pm \mathrm{SD}$ or median (interquartile range), unless otherwise stated. BMI: body mass index; GOLD: Global Initiative for Chronic Obstructive Lung Disease; BD: bronchodilator; FEV $\mathrm{F}_{1}$ : forced expiratory volume in $1 \mathrm{~s}$; FVC: forced vital capacity. ${ }^{*}: p<0.05 ;{ }^{\star *}: p<0.01 ;{ }^{\star \star *}: p<0.001 ;{ }^{* \star * *}: p<0.0001$ compared with healthy controls; $: p<0.05 ;{ }^{\# \#}: p<0.01 ;{ }^{\# \#}: p<0.001 ;{ }^{\# \# \#: ~} p<0.0001$ compared with asthma. 
TABLE 2 Baseline mean and variability of oscillometry measurements for study subjects

\begin{tabular}{|c|c|c|c|}
\hline & Healthy & Asthma & COPD \\
\hline$R_{\mathrm{rs}_{5}}\left(\mathrm{cmH}_{2} \mathrm{O} \cdot \mathrm{s} \cdot \mathrm{L}^{-1}\right)$ & $3.1 \pm 1.0$ & $4.9 \pm 2.0^{\star}$ & $5.0 \pm 1.7^{\star \star}$ \\
\hline z-score $R_{\mathrm{rs}_{5}}$ & $-0.5 \pm 3.0$ & $1.2 \pm 1.2$ & $1.8 \pm 1.2^{\star \star}$ \\
\hline $\operatorname{CoV}\left(R_{\mathrm{rs}_{5}}\right)(\%)$ & $6.7 \pm 4.7$ & $9.7 \pm 5.7$ & $12.6 \pm 11.2$ \\
\hline ICC $R_{\mathrm{rs}_{5}}$ & 0.97 & 0.98 & 0.93 \\
\hline$X_{\mathrm{rs}_{5}}\left(\mathrm{cmH}_{2} \mathrm{O} \cdot \mathrm{s} \cdot \mathrm{L}^{-1}\right)$ & $-1.3 \pm 0.5$ & $-2.8 \pm 2.2$ & $-3.9 \pm 3.0^{\star \star \star}$ \\
\hline z-score $X_{\mathrm{rs}_{5}}$ & $-0.3 \pm 1.8$ & $-2.7 \pm 3.8$ & $-4.7 \pm 4.9^{\star \star \star}$ \\
\hline $\mathrm{ICC} X_{\mathrm{rs}_{5}}$ & 0.98 & 0.95 & 0.97 \\
\hline$X_{\mathrm{rs}_{5}} \cdot \operatorname{in}-X_{\mathrm{rs}_{5}} \cdot \mathrm{ex}\left(\mathrm{cmH}_{2} \mathrm{O} \cdot \mathrm{s} \cdot \mathrm{L}^{-1}\right)$ & $-0.7 \pm 0.3$ & $1.0 \pm 3.1$ & $1.7 \pm 3.0^{\star \star}$ \\
\hline$R_{\mathrm{rs}_{5}}-R_{\mathrm{rs}_{19}}\left(\mathrm{cmH}_{2} \mathrm{O} \cdot \mathrm{s} \cdot \mathrm{L}^{-1}\right)$ & $0.2 \pm 0.4$ & $1.4 \pm 1.2^{\star \star}$ & $1.7 \pm 0.8^{\star \star \star}$ \\
\hline $\mathrm{AX}\left(\mathrm{cmH}_{2} \mathrm{O} \cdot \mathrm{s} \cdot \mathrm{L}^{-1}\right)$ & $5.2 \pm 4.2$ & $28.1 \pm 29.6^{\star}$ & $38.7 \pm 32.4^{\star \star \star}$ \\
\hline VT (L) & $0.7 \pm 0.3$ & $1.0 \pm 1.2$ & $0.8 \pm 0.2$ \\
\hline
\end{tabular}

Data are presented as mean \pm SD unless otherwise stated. Variables were calculated from the first three consecutive 30-s measurements using the sD-based quality control method, with no attempt to reduce within-session coefficient of variation (CoV). AX: reactance area; BD: bronchodilator; ex: expiratory; $\mathrm{FEV}_{1}$ : forced expiratory volume in $1 \mathrm{~s}$; FVC: forced vital capacity; in: inspiratory; $R_{\mathrm{rs}_{5}}$ : resistance of the respiratory system at $5 \mathrm{~Hz}, R_{\mathrm{rs}_{19}}$ : resistance of the respiratory system at $19 \mathrm{~Hz}$, VT: tidal volume; $X_{\mathrm{rs}_{5}}$ : reactance at $5 \mathrm{~Hz}$. ${ }^{\star *}$ : $p<0.01$; ${ }^{* \star *}: \mathrm{p}<0.001$ compared with healthy controls.

Effect of measurement number on oscillometry parameters

When considering all available measurements, there was no overall effect of measurement number on oscillometry parameters across all subject groups. Specifically, when including an increasing number of measurements from four to eight, neither the mean $R_{\mathrm{rS}_{5}}$ nor the $\operatorname{CoV}\left(R_{\mathrm{rs}_{5}}\right)$ (\%) were significantly different from including the first three measurements (figure $1 \mathrm{a}$ and $\mathrm{b}$, respectively).

When considering only the three closest $R_{\mathrm{rS}_{5}}$ values from the available measurements, the mean $R_{\mathrm{rS}_{5}}$ did not change with increasing the number of measurements from four to eight (figure 2a). However, taking five or more measurements resulted in a significant reduction of $\operatorname{CoV}\left(R_{\mathrm{rs}_{5}}\right)$ for all subject groups (figure $2 \mathrm{~b}$ ). In health, the $\operatorname{CoV}\left(R_{\mathrm{rs}_{5}}\right)$ decreased from $6.7 \pm 4.7 \%$ at three measurements to $1.0 \pm 0.5 \%$ by the eighth measurement $(\mathrm{p}<0.001)$. In asthma and COPD this decrease was from $9.7 \pm 5.7 \%$ to $1.7 \pm 1.4 \%$, and 12.6 $\pm 11.2 \%$ to $2.0 \pm 1.6 \%$, respectively ( $\mathrm{p}<0.0001$ for both).

The number of measurements required to achieve target cut-off

In order for at least $95 \%$ of subjects to fall within a target $\mathrm{CoV}\left(R_{\mathrm{rs}_{5}}\right)$ of $\leqslant 5 \%$, at least five measurements were needed for health, and at least eight for asthma (figure 3). The COPD group, on the other hand, were unable to obtain this threshold even when taking eight measurements. When the threshold was set at $\leqslant 10 \%$, at least four, five and six measurements were needed in health, asthma and COPD, respectively. When the threshold was set at $\leqslant 15 \%$, at least four measurements were needed for health and asthma, and
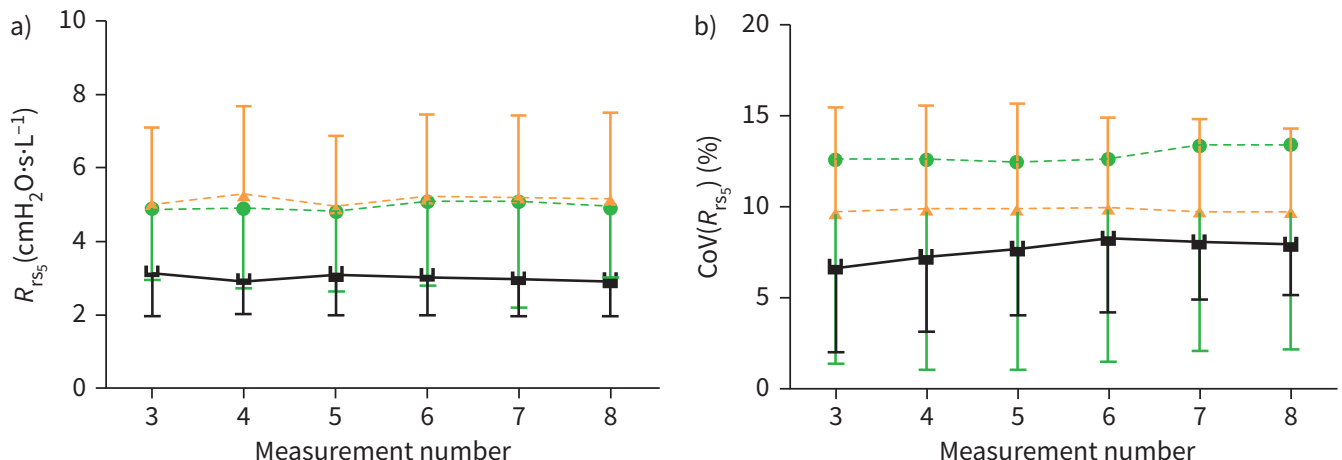

FIGURE 1 The mean and within-session variability of total $R_{\mathrm{rs}}$ at $5 \mathrm{~Hz}$ does not change with an increasing number of measurements. The mean (a) and $\mathrm{CoV} \%$ (b) of $R_{\mathrm{rs}_{5}}$ was calculated after three to eight 30-s oscillometry measurements were carried out on healthy individuals (black squares) and patients with asthma (orange triangles) or COPD (green circles; $\mathrm{N}=15$ for all groups). CoV: coefficient of variation; $R_{\mathrm{rs}_{5}}$ : total resistance at $5 \mathrm{~Hz}$. 

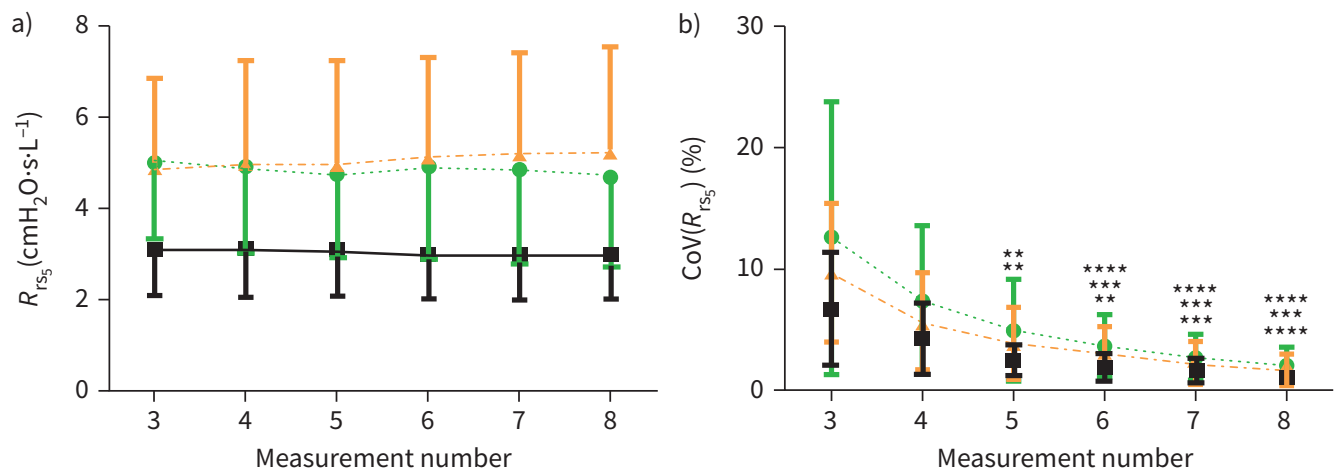

FIGURE 2 Selecting the closest three $R_{\mathrm{rs}_{5}}$ values that were taken over four to eight measurements significantly reduced the CoV compared to when only three measurements were taken. The mean (a) and CoV (b) of total $R_{\mathrm{rs}_{5}}$ was calculated when the three closest measurements were selected from four to eight 30-s oscillometry measurements carried out on healthy individuals (black squares) and people with asthma (orange triangles) or COPD (green circles; $N=15$ for all groups). ${ }^{\star *}: p<0.01 ;{ }^{* \star \star}: p<0.001 ;{ }^{* \star \star}: p<0.0001$ compared with measurement 3 of the respective patient group. CoV: coefficient of variation; $R_{\mathrm{rs}_{5}}$ : resistance of the respiratory system at $5 \mathrm{~Hz}$.

five in COPD. At $\leqslant 20 \%$ threshold, at least three measurements were needed for health and asthma, and four in COPD.

The effect of quality control method on oscillometry parameters

The effect of quality control method of oscillometry parameters on the above findings was examined by comparing results generated by the sD-based method, to that produced with the "manual”, "combined" and
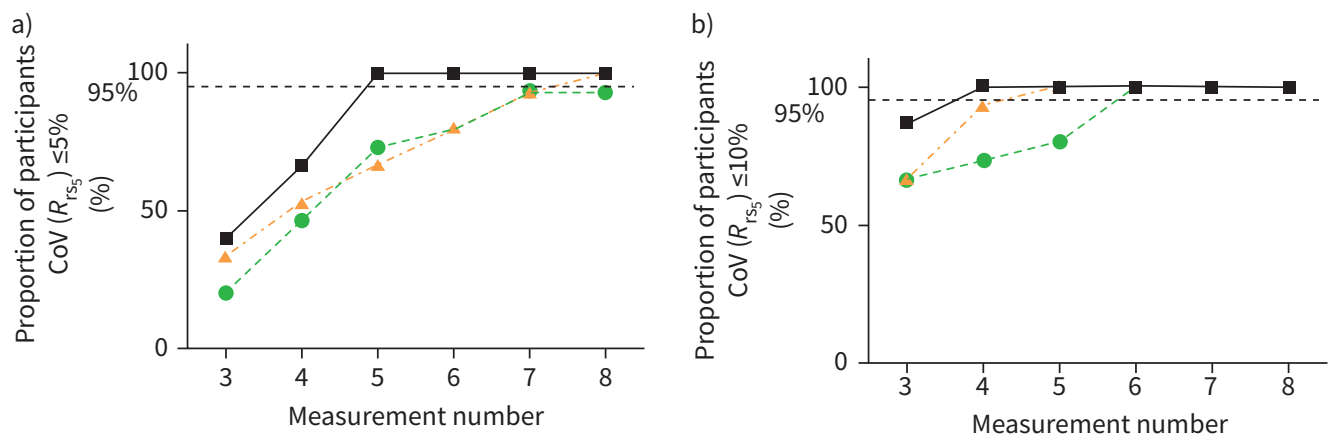

c)

d)
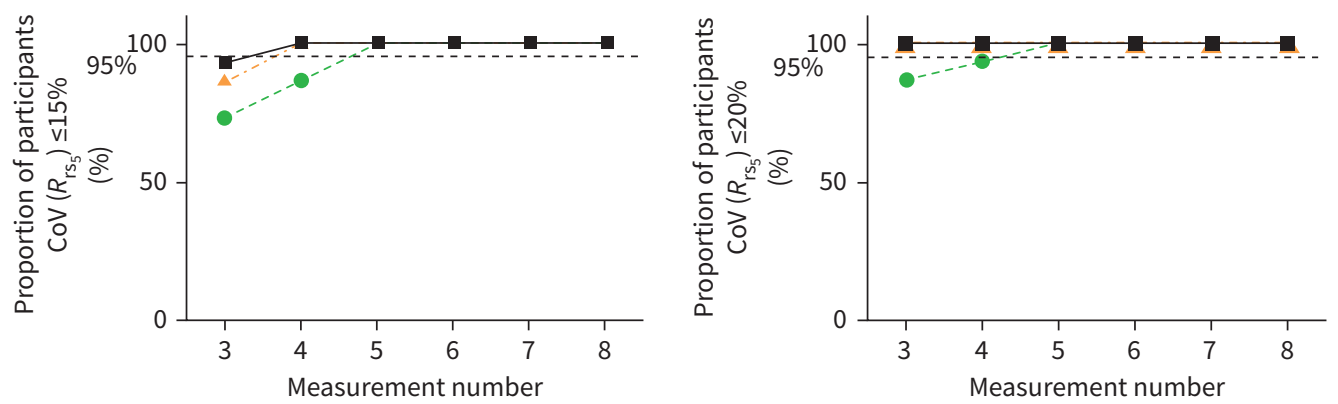

FIGURE 3 Asthmatic and COPD patients require a greater number of measurements to achieve a CoV $R_{\mathrm{rs}}$ at $5 \mathrm{~Hz}$ of $\leqslant 5 \%, \leqslant 10 \%, \leqslant 15 \%$ or $\leqslant 20 \%$. The number of measurements needed for $95 \%$ of the healthy (black squares), asthmatic (orange triangles) or COPD (green circles) populations to obtain a $\operatorname{CoV}\left(R_{\mathrm{rs}_{5}}\right)$ of $\leqslant 5 \%$ (a), $\leqslant 10 \%$ (b), $\leqslant 15 \%$ (c), $\leqslant 20 \%$ (d), when the closest three measurements were selected from four to eight measurements ( $\mathrm{N}=15$ for all groups). $\mathrm{CoV}$ : coefficient of variation; $R_{\mathrm{rs}_{5}}$ : resistance of the respiratory system at $5 \mathrm{~Hz}$. 
"none” quality control methods (see supplementary material, Tables S1-S4, and Figures S1-S4). Our observations were consistent regardless of the quality control methods employed.

\section{Discussion}

Summary of findings

In this study we examined the within-session variability of oscillometry in a group of healthy controls and patients with asthma and COPD, in order to determine the optimal number of measurements required to achieve an acceptable $\mathrm{CoV}$, within a single testing session. We demonstrated that increasing the number of measurements increases the chances of obtaining at least three measurements within a set target for within-session CoV. Furthermore, in order for the majority of participants to achieve a target $\operatorname{CoV}\left(R_{\mathrm{rs}_{5}}\right)$ of $\leqslant 10 \%$, we required at least four, five and six measurements in the health, asthma and COPD groups, respectively.

\section{Effect of number of measurements on within-session CoV}

Increasing the number of oscillometry measurements (up to eight) did not reduce the within-session variability in healthy individuals or patients with obstructive airway diseases, when all measurements were included. However, it did allow for the best three measurements to be selected, thus increasing the probability of decreasing the $\mathrm{CoV}$ from when only the first three or all eight consecutive measurements were chosen. The lack of statistical differences in $R_{\mathrm{rS}_{5}}$ in all these cases suggests that increasing the number of measurements in a clinical session does not provide any additional information in terms of the properties of the airways. Although this latter finding should be interpreted with caution given the small sample sizes in our study, it is supported by a previous study [7].

The within-session $\mathrm{CoV}$ values reported in this study (table 2, i.e. 6.7\%, 9.7\% and 12.6\% for health, asthma and COPD, respectively) were generally higher than those demonstrated in a previous study (4.2\%, $6.6 \%$ and $5.8 \%$, respectively), where 60 -s rather than 30 -s measurements were used [9]. Measurement duration has been shown to reduce within-session $\mathrm{CoV}$ [7]. Our results are closer to those obtained from 30 -s measurements in another study, which used a manual exclusion quality control approach $(9 \%, 8 \%$ and $6 \%$, respectively) [7]; however, in contrast to our findings, both those studies reported lower within-session $\mathrm{CoV}$ for COPD compared to asthma. In a more recent study [11], we were able to calculate within-session $\mathrm{CoV}$ from a larger clinical dataset using manually quality-controlled measurements in triplicate, which confirms higher values in disease and more similar values between asthma and COPD (Table S5); the 95th centiles for health, asthma and COPD in that dataset were $12.5 \%, 13.3 \%$ and $17.8 \%$, respectively. It is perhaps not surprising that here we report higher mean $\mathrm{CoV}$ values, given that unlike in previous studies, no attempt was made in our study to reduce the CoV during data collection, due to the stated aims of the study.

Within-session variability expressed as ICCs $(0.97,0.98$ and 0.93 , respectively) were more comparable to other studies in the literature $[12,13]$. These results emphasise that ICC is a more reliable group-based measure of within-session variability than $\mathrm{CoV}$, as the latter is more susceptible to outliers and values close to zero, and is a poor indication of quality for $X_{\mathrm{rs}}$.

\section{Validity of setting CoV cut-offs}

ERS standards currently recommend a cut-off of $10 \%$ in adults and $15 \%$ in children as a quality control target, as is common practice. We have shown that selecting the closest three of four to eight measurements allowed the subject groups to reach target thresholds of $\operatorname{CoV}\left(R_{\mathrm{rs}_{5}}\right)$ of $\leqslant 5 \%, \leqslant 10 \%$ and $\leqslant 15 \%$, which was not generally obtainable when using only the first three consecutive measurements. Furthermore, although a target $\operatorname{CoV}\left(R_{\mathrm{rs}_{5}}\right)$ of $\leqslant 10 \%$ was achievable across health, asthma and $\mathrm{COPD}$, a greater number of measurements was required in disease. When the $\mathrm{CoV}$ cut-off was set at $\leqslant 10 \%$, at least four measurements were needed in healthy subjects and at least five and six measurements in asthma and COPD, respectively. The extended testing and repeated coaching involved may not be practical in a busy clinical laboratory setting, where the patient may also have to undergo multiple other tests.

In addition, our results provide additional evidence that increased variability is probably itself an intrinsic marker of obstructive airway diseases, and not just of measurement quality per se. This is supported by the finding that $\mathrm{CoV}$ was higher in the asthma and COPD groups, coupled with the observation that within-session variability was correlated with degree of airway disease (data not shown), compared to in health. Higher variability of respiratory impedance in disease and worsening disease status has also been observed in multiple studies in adults [9, 14-17] as well as children [18, 19], and may reflect increased instability in the airways or heterogeneity of accessible lung units [20, 21]. 
For these reasons, we propose that rather than making repeated measurements in an attempt to reduce CoV, quality control efforts should first and foremost focus on excluding artefacts and outlier breaths, which has previously been shown to impact within-session $\mathrm{CoV}$ [8]; where the $R_{\mathrm{rs}}$ frequency and $X_{\mathrm{rs}}$ frequency spectra are available from some software platforms, these could further be used to determine outlier recordings. A target within-session $\mathrm{CoV}$ of $10 \%$ is achievable within three measurements for the majority of the population, and can be an indicator of a high-quality test. However, for some individuals, particularly patients with respiratory disease, a higher $\mathrm{CoV}$ is not necessarily an indicator of poor quality. Based on this study and the upper limits of CoV observed in disease, we suggest that a more relaxed threshold of, for example, $15 \%$ or $20 \%$ may be classified as "reportable" quality, perhaps within the context of a grading system.

\section{Sensitivity analysis using different quality control criteria}

We investigated how our main findings were altered by the use of four different methods of post hoc quality control, aimed at removing points within measurements that were outliers and/or patient-derived artefacts, present during data collection. It would also have presented an opportunity to determine which quality control method provided the most replicable within-session CoV. However, we saw that the quality control method chosen had minimal effect on how $\operatorname{CoV}\left(R_{\mathrm{rs}_{5}}\right)$ varied with number of measurements. In particular, when comparing the automatic quality control (SD method) with the manual method (a more stringent quality control method), the results did not vary significantly, with only a slightly higher chance of getting more acceptable results in asthma but not COPD at $\operatorname{CoV}\left(R_{\mathrm{rs}_{5}}\right)$ of $\leqslant 15 \%$. This lack of dependence on quality control method is observed despite the fact that the default SD method is relatively permissive, allowing values within up to 5 sDs to be included, whereas the manual method would have excluded whole breaths (including high values) that appeared aberrant. It is also in contrast to our previous findings in children comparing quality control measures based on the 5-SD method, 3-SD method, and manual exclusion of whole breaths - only the latter had a significant impact on within-session CoV [8]. It may be that in our study, sufficient artefact-free breaths were captured within a 30-s recording to provide an accurate and robust estimate of $R_{\mathrm{rs}_{5}}$, and consequently of within-session $\mathrm{CoV}$. It is also worth noting that our findings showed it is possible to achieve excellent reliability (in terms of ICC) from just three measurements.

\section{Limitations}

The sample sizes were relatively small, and the asthma and COPD groups in our study were older and contained a range of disease severities. However, the sample size is comparable to previous studies examining within-session variability [7, 9, 19], and the age and heterogenous nature of the disease groups was an accurate representation of the populations attending respiratory clinics. Despite these limitations the results provide valuable insight for further development of oscillometry standard operating procedures. We also did not investigate effects on the $\mathrm{CoV}$ of $X_{\mathrm{rs}}$ parameters, as the high susceptibility of $X_{\mathrm{rs}}$ to outliers (due to its proximity to zero) limits its practical utility as a quality control measure in the first place.

\section{Conclusion}

In conclusion, we demonstrated that increasing the number of measurements does not alter oscillometric measures of airway resistance, although it does increase the chances of obtaining at least three measurements within a set target. However, and more importantly, within-session variability is greater in disease, and while the recommended target cut-off of $\operatorname{CoV}\left(R_{\mathrm{rs}_{5}}\right) \leqslant 10 \%$ is generally achievable, the higher number of measurements required to achieve this target, particularly in disease, may not be practical in a clinical setting. Hence, quality control should be focused first on removing artefacts and outliers, and a within-session $\mathrm{CoV} \leqslant 10 \%$ viewed as a marker of high quality as recommended by current ERS standards, but here we provide evidence that a within-session CoV of up to 15-20\% (particularly in disease) is not necessarily a marker of poor quality and should be reportable. Our findings can be used in conjunction with current oscillometry guidelines and recommendations and may help in the development of future recommendations on methodology.

Acknowledgements: We would like to acknowledge the study participants for volunteering the time and effort required to conduct this study.

Conflict of interest: L.M. Harkness is currently an employee of GSK but the work in this manuscript was conducted prior to that employment. K. Patel has nothing to disclose. F. Sanai has nothing to disclose. S. Rutting has nothing to disclose. A.M. Cottee has nothing to disclose. C.S. Farah has nothing to disclose. R.E. Schoeffel has nothing to disclose. G.G. King reports grants, personal fees and nonfinancial support from AstraZeneca, Boehringer Ingelheim, Chiesi, GlaxoSmithKline, Menarini, MundiPharma and Novartis; unrestricted research grants from NHMRC, 
Boehringer Ingelheim, CycloPharma, GlaxoSmithKline, Menarini, MundiPharma, and philanthropic individuals and societies; and nonfinancial and other support from Restech, Italy during the conduct of the study. C. Thamrin has a patent WO $2006130922 \mathrm{~A} 1$ issued, which is broadly relevant to the work. In addition, C. Thamrin has intellectual property arrangements with THORASYS Medical Systems and Restech srl relating to research collaborations, but does not have any financial relationships with either company.

\section{References}

1 Oostveen E, MacLeod D, Lorino $\mathrm{H}$, et al. The forced oscillation technique in clinical practice: methodology, recommendations and future developments. Eur Respir J 2003; 22: 1026-1041.

2 Bates JH, Irvin CG, Farre R, et al. Oscillation mechanics of the respiratory system. Compr Physiol 2011; 1: 1233-1272.

3 Calverley PMA, Farré R. Oscillometry: old physiology with a bright future. Eur Respir J 2020; 56: 2001815.

4 Zimmermann SC, Tonga KO, Thamrin C. Dismantling airway disease with the use of new pulmonary function indices. Eur Respir Rev 2019; 28: 180122.

5 Beydon N, Davis SD, Lombardi E, et al. An official American Thoracic Society/European Respiratory Society statement: pulmonary function testing in preschool children. Am J Respir Crit Care Med 2007; 175: 1304-1345.

6 King GG, Bates JH, Berger K, et al. Technical standards for respiratory oscillometry. Eur Respir J 2019; 53: 1801028 .

7 Watts JC, Farah CS, Seccombe LM, et al. Measurement duration impacts variability but not impedance measured by the forced oscillation technique in healthy, asthma and COPD subjects. ERJ Open Res 2016; 2 : 00094-2015.

8 Robinson PD, Turner M, Brown NJ, et al. Procedures to improve the repeatability of forced oscillation measurements in school-aged children. Respir Physiol Neurobiol 2011; 177: 199-206.

9 Timmins SC, Coatsworth N, Palnitkar G, et al. Day-to-day variability of oscillatory impedance and spirometry in asthma and COPD. Respir Physiol Neurobiol 2013; 185: 416-424.

10 Quanjer PH, Stanojevic S, Cole TJ, et al. Multi-ethnic reference values for spirometry for the 3-95-yr age range: the global lung function 2012 equations. Eur Respir J 2012; 40: 1324-1343.

11 Rutting S, Badal T, Wallis R, et al. Long-term variability of oscillatory impedance in stable obstructive airways disease. Eur Respir J 2021; 58: 2004318.

12 Gonem S, Corkill S, Singapuri A, et al. Between-visit variability of small airway obstruction markers in patients with asthma. Eur Respir J 2014; 44: 242-244.

13 Kuo CR, Jabbal S, Lipworth B. I Say IOS You Say AOS: comparative bias in respiratory impedance measurements. Lung 2019; 197: 473-481.

14 Neild JE, Twort CHC, Chinn S, et al. The repeatability and validity of respiratory resistance measured by the forced oscillation technique. Respir Med 1989; 83: 111-118.

15 Van den Elshout FJJ, Folgering HTM, Van de Woestijne KP. Variations of respiratory impedance with lung volume in bronchial hyperreactivity. Chest 1990; 98: 358-364.

16 Gimeno F, van der Weele LT, Koëter GH, et al. Variability of forced oscillation (Siemens Siregnost FD 5) measurements of total respiratory resistance in patients and healthy subjects. Ann Allergy 1993; 71: 56-60.

17 Que CL, Kenyon CM, Olivenstein R, et al. Homeokinesis and short-term variability of human airway caliber. J Appl Physiol (1985) 2001; 91: 1131-1141.

18 Lall CA, Cheng N, Hernandez P, et al. Airway resistance variability and response to bronchodilator in children with asthma. Eur Respir J 2007; 30: 260-268.

19 Robinson PD, Brown NJ, Turner M, et al. Increased day-to-day variability of forced oscillatory resistance in poorly controlled or persistent pediatric asthma. Chest 2014; 146: 974-981.

20 Gobbi A, Dellacá RL, King G, et al. Toward predicting individual risk in asthma using daily home monitoring of resistance. Am J Respir Crit Care Med 2017; 195: 265-267.

21 Zimmermann SC, Huvanandana J, Nguyen CD, et al. Day-to-day variability of forced oscillatory mechanics for early detection of acute exacerbations in COPD. Eur Respir J 2020; 56: 1901739. 